\title{
THE LABORS OF INTERNET-ASSISTED ACTIVISM: OVERCOMMUNICATION, MISCOMMUNICATION, AND COMMUNICATIVE OVERLOAD
}

Rasmus Kleis Nielsen

\section{AUTHOR NOTE}

Rasmus Kleis Nielsen is a PhD student in Communications at Columbia University. He would like to thank Dave Karpf, the participants at the Politics: Web 2.0 conference at Royal Holloway, University of London, April 17-18, 2008, the three anonymous reviewers, and in particular Andrew Chadwick for comments and constructive criticism. Correspondence concerning this article should be addressed to rkn2103@columbia.edu

\section{KEYWORDS}

internet, ICTs, political participation, campaigns, elections, activism, ethnography, participantobservation 


\begin{abstract}
This article analyzes the use of Internet elements in political activism through a close ethnographic case study of a volunteer group involved in the 2008 U.S. presidential primary. Whereas the literature on political activism has generally argued that the Internet provides lowcost communication that facilitates collective action, this case highlights the labors that accompany Internet-assisted activism. The analysis, based upon participant-observation, identifies related problems of overcommunication, miscommunication, and communicative overload with which the activists struggled. Drawing on concepts taken from science and technology studies, the article argues that these problems have socio-technical roots and arise from the specific affordances of an increasing number of Internet elements. Even as such elements reduced the up-front costs associated with communication for the sender, they help generate new transaction costs when they are integrated into heterogeneous assemblages with no shared communication protocol, single infrastructure or clear exostructure, or any other means of tempering the tendency for participating Internet-assisted activists and groups to always communicate more.
\end{abstract}


In the aftermath of the February 5 round of the 2008 U.S. presidential primary, I was left with one immediate puzzle: why did the activists that I had followed for a year go more or less off-line in the final days of the campaign? In the run-up to the election, at the very point where I had assumed that the supposed strengths of the Internet — fast, easy, low-cost communication — would be most helpful, the activists threw up their hands in frustration and turned to other tools. They stopped updating their websites, let the social networking tools rest, scaled back on the emailing, and started to coordinate mainly by phone and face-to-face meetings. Various Internet elements, from email and static webpages to cutting-edge social software tools, had been integral to their mobilization, and were often praised. But now, when the group had to perform, Internet-assisted activism turned out to be more laborious than anyone had expected.

Based on a participant-observation study of a single campaign, this paper addresses the question of how Internet elements are integrated into political activism. I analyze the labors that now accompany Internet-assisted activism in the form of overcommunication, miscommunication, and communicative overload. As I will show below, neither of the two dominant views of the Internet and collective action capture the concrete problems faced by the activists that I studied. One view has it that low-cost communications facilitate collective action. My case highlights the problems it creates. Another view warns of potentially paralyzing information overload. But the activists were not paralyzed, and their problems arose not from information in general, but from Internet-assisted communication in particular.

The surprising decision to go offline in the last days of the primary was just one consequence of the labors identified here. More broadly, the problems suggest some of the 
limitations and unrealized potentials of Internet-assisted activism in electoral politics. And activists elsewhere too may find that the very Internet elements that help them maintain connections with a large community of interest turn become less useful when they turn to action. As they canvassed, leafleted, and phone banked in the primary, volunteers and organizers struggled with increasing problems of overcommunication, miscommunication, and communicative overload. These hampered attempts to get things done, and ultimately led people to momentarily side-step the Internet and rely on off-line organizing among a much smaller core group of activists.

\section{PARTICIPANT-OBSERVATION IN A PRIMARY CAMPAIGN}

The activists who were the subject of the fieldwork for this paper were organized around what was, at the time, considered to be one of several credible candidacies for the Democratic Party's 2008 presidential nomination. The literature on political parties and campaigns suggests that as recently in the 1990 s, volunteers were not always valued, the indifference sometimes reaching a point where professional staffers simply turned away interested activists, because they did not know what to do with them (Weir \& Ganz, 1997). Politics was not considered a place for amateurs. This attitude seems to have changed somewhat. In April of 2007, the sites of leading primary candidates - to take quotes from the Hillary Clinton, Barack Obama, and John McCain webpages - all invited the visitor to "join our team", "join the movement", and "get involved". Activists are now considered a valuable resource. As Hindman (2008) and Vaccari (2008) have pointed out, volunteer involvement is one part of electoral campaigns where the Internet is seen 
as particularly promising, and the medium through which the invitation to take part is increasingly extended. The group studied was made of up people who took up this invitation. They started organizing around their favorite candidate months before the formal and professional campaign organization came to town.

The group I followed was chosen for several reasons. First, the aim was to examine electoral politics rather than the more contentious social movements that are often analyzed as examples of Internet-assisted activism (the alternative globalization movement, the Zapatistas, the radical far right, etc). In electoral politics, most work has focused on how the Internet works from a consultant and staff perspective (Howard, 2006) or from a more general and outside perspective (Bimber \& Davis, 2003; Foot \& Schneider, 2006). The aim was to supplement these studies with an analysis of activists and their point of view. ${ }^{1}$ Second, this campaign was considered quite successful in terms of fund-raising and recruitment, and it had considerable stakes in the primary in the city in question, so it was reasonable to expect that people could do their best and not be starved of resources, as they would probably be in a non-competitive campaign or an irrelevant election. Thirdly, the aim was to circumnavigate a pronounced tendency in much work on the Internet and politics, namely the study of phenomena that have retrospectively been judged spectacularly successful in one or more ways-Jesse Ventura's gubernatorial campaign, Howard Dean's primary campaign in 2004, and MoveOn, for example. With this project, there were no a priori reasons to expect that this would be an extraordinary campaign and that was deliberate choice.

From January 2007 to February 2008, I engaged in participant-observation in the volunteer group. For the first eight months, activity was intermittent, and so were my field trips.

\footnotetext{
${ }^{1}$ A note on terminology here: most of the people I talked to called themselves 'activists', though most staffers would probably call them 'volunteers'. I have chosen to stay true to their self-identification, just as I do not call the staffers 'the kids', despite the fact that a large number of activists used that term to refer to them.
} 
From September to November 2007, activity picked up, and as the first primaries drew to a close in December, it increased even further. In total, I attended 32 planning meetings, social happenings, and action events, and observed a further 6 events anonymously from a distance. I also spent a weekend canvassing with people from the volunteer group in a nearby state, and an extended weekend leading up to the primary following the group full-time in the city itself. I visited several different parts of the group, ranging from geographically or affinity-based subgroups to city-wide coordination committees. During and after the campaign, I conducted 10 semi-structured interviews with various activists, ranging from one-off and occasional volunteers to people who were basically full-time unpaid organizers. I promised everyone I spoke to, in the field or in interviews, full anonymity. At events, I introduced myself as a researcher whenever I had the opportunity, helped with basic work whenever someone asked me to, but avoided contributing to strategy sessions and discussions of organizing, even when people tried to elicit my opinions. Parallel to the offline field research, I tracked the group's online presence, archiving hundreds of emails and dozens of webpage screenshots.

To make sense of the analysis that follows, it is important to bear in mind that a campaign for an important election in a big city is a sprawling entity, and I deal with it here from an activist perspective only. The volunteer groups I followed are only one part of what can be usefully understood as an assemblage: a whole made up of heterogeneous interdependent parts operating in concert relative to a specific project (De Landa, 2006). Early in 2007, dozens of activists met at a handful of locations around the city. In the fall, hundreds gathered at scores of happenings. In the winter of 2007/2008, thousands took part in hundreds of events. I did not analyze the socio-economic or demographic composition of the group systematically, but my sense was that these people, like most people who get involved in primaries, were predominantly 
well-educated, well-off, and well-informed, and many of them were seasoned activists (cf.

Johnson \& Gibson, 1974). Eventually, the campaign assemblage included the formal campaign organization that came to town in October 2007 (manned by paid staffers and full-time volunteers or interns, who often wanted jobs too), the expansive volunteer group I followed from January, and various affiliated organizations and groups who aligned themselves with the candidate in question late in the election. The wider assemblage drew together a population organized around two overlapping but not identical communities: one centered on an interest in the candidate in question, and a desire to be 'part of something', and one centered around a desire for action, or a desire to 'do something'. The whole effort was tied together by a shared identification with the candidate, by the use of partially overlapping infrastructures and exostructures to communicate and coordinate, and by the common desire to do well in the upcoming primary.

THEORIZING INTERNET-ASSISTED ACTIVISM

The objects of analysis here are the use of Internet elements in activist practices. By 'elements', I mean individual applications, ranging from the particular (an individual static website), through to the general (for instance Facebook), and the ubiquitous (email). Very different Internet elements are used for many different purposes by different parts of political assemblages, from fundraising and constituent relations management through to opposition research and to press relations. In this volunteer group, various Internet elements were mainly used to assemble, coordinate, and empower activists through communication. 
It has often been noted that activism arises out of social networks (cf. Gould, 1995; Snow \& Ekland-Olson, 1980; Verba et al, 1995). Whereas these networks' organizations (say, churches, neighborhood associations, decision-making structures) are often analyzed, their adjoining technical elements (leaflets, broadcasts, or in this case Internet applications) have not been subject to the same attention. The role of technology needs to be brought into the study of activism because it is predominantly through elements ranging from membership lists to communication devices that people become capable of extending themselves and organize beyond the time/space constraints of the localized networks from which many groups originate, but which are rarely in themselves sufficient to challenge the extra-local forces that affect our lives (see Sreberny-Mohammadi \& Mohammadi, 1994, Roscigno \& Danaher, 2001, and Shumate \& Pike, 2006 for some of the few exceptions to the tendency to ignore questions of communication in research on movements and organizing). If activism is in large part based on shared purposes, repertoires, and activities, surely whatever makes the sharing possible is worthy of study. The use of various Internet elements in this campaign provides an example of an infrastructure largely created and governed by activists as well as the appropriation and use of an exostructure of elements beyond their control. This extended purely social relations into a larger socio-technical campaign assemblage.

Following the example offered by science and technology scholars such as Bruno Latour (1986; 1987; 2005), I analyze these elements as parts of assemblages that involve particular objects, subjects, and semantic resources as they are combined and recombined in action. Though I am interested here in the use of Internet elements in particular, it is important to keep in mind that the activists, as described above, at times went offline, and also continuously relied on other media for communication: the activism I analyze here as Internet-assisted is also 
assisted by other ICTs like cell phones, and by old-fashioned landlines, cars, and clipboards. As has been argued elsewhere, the extent to which most of what we observe today represents a distinct kind of 'Internet', 'cyber', or 'Web' activism is debatable (Tilly, 2004). Internet elements are not the only objects integral to activism, nor are they even the most important. The postal system remains central to many membership-based activist groups. Sometimes, existing socio-technical assemblages are abandoned or simply ignored, but in many cases they are simply further expanded to include online sites and practices.

The focus on assemblages, communication, infrastructures and exostructures highlights the work that goes into what Latour calls 'assembling the social'. This approach is not about the impact of 'the Internet' on some abstract generality like 'activism.' It is about the use or lack of use, for instance, of certain aspects of a campaign website or of Google groups in activism. In practice, the activists confronted and used the totality of affordances on the Internet in a modular fashion. Some crafted their own toolsets across a wide range of potentially useful sites, while others made use of only a few online tools. We might call this 'cloud activism', in reference to the notion of 'cloud computing,' i.e., activism based on a structure that the user does not control or own the way they would an individual centralized personal computer or intranet, but which is put together from a wide menu of services. Cloud activism does not have an online or offline locus. It is not tied to any single page; the campaign website is just one of many. It is not tied to a single application: even email, ubiquitous as it is, is only one of numerous applications. But cloud activism employs and integrates various mundane and sometimes esoteric infrastructural and exostructural elements in communication meant to mobilize and coordinate collective action. The advantage of the approach adopted here is that it allows one to see how the modularity of the Internet elements - and the abundance of modules available - combined the oft-mentioned 
lowered costs of communication with the less often recognized labors I focus on here. When there are so many applications, all free or cheap, and all quick and easy to use, why not use them all? Why choose between the campaign website, Meetup, and Facebook, when one can have them all, and many more? Eventually, the costs become apparent, and the labors sets in.

Overcommunication, miscommunication, and communicative overload are curious phenomena. They run counter to dominant ideas about the role of Internet in activism, and they point to troubles in volunteer groups that are more commonly associated with full-time knowledge-workers in professional organizations. The prevailing consensus of the last decade in research on politics and social movements is that the Internet lowers the barriers for collective action because it reduces transaction costs (cf. Bennett, 2003; Bimber \& Davis 2003; Bimber et al, 2005; Della Porta et al., 2006; Foot \& Schneider, 2006; Garrett, 2006; Klein 1999; Tilly, 2004). This argument is at the heart of more popular celebrations of Internet-assisted peoplepowered politics too (Rheingold, 2002; Trippi, 2004). The bases of this idea have typically been the technical properties of Internet-mediated communication, though their everyday use has rarely been scrutinized in detail. However, a very different point has been made in the largely separate literatures on organizational communication and computer-mediated interaction. There, researchers have argued that problems of information overload have been exacerbated by the Internet and that this may inhibit collective action by increasing transaction costs (Eppler \& Mengis, 2004; Edmunds \& Morris, 2000). This point too has had its popularizers (cf. Shenk, 1997). Even if the precise nature of information overload is, as Himma (2007) has pointed out, somewhat ambiguous, the basic idea that organizations and individuals can be paralyzed by an information supply that exceeds processing capacity seems intuitively plausible. It is also backed 
by a large number of empirical studies, almost all in professional and commercial organizations, such as businesses trading in information, technology, and services (cf. Zeldes et al, 2007).

The labor identified in my case is a product of forces that the idea of low-cost communication does not take into account: the decreased up-front costs for communicators facilitate an explosion in the number of communications, communicators, and forms of communication, and this explosion in turn introduces new transaction costs. These costs require empirical exploration, not least because in electoral campaigns they are experienced by predominantly part-time activists, and not by the knowledge workers typically discussed in the organizational communication literature. The information overload literature deals mainly with wage earners and other captive audiences, rather than volunteers.

To provide illustrations of the character of these three problems, I will now discuss each in turn, before proceeding to a concluding discussion.

THE PROBLEM OF OVERCOMMUNICATION: “I JUST IGNORE IT, MAN.”

During the last four days of the primary I received 45 emails from various parts of the campaign assemblage. If it were not for the fact that much of the coordination had gone off-line by then, it would have been much more than that. Most of the emails were long, filled with pleas to volunteer and donate money, replete with detailed instructions as to how I could help. I received emails from the national campaign office, from the local campaign office, from neighborhood groups, affinity groups, from individual organizers, from affiliated organizations, and messages through some of the external sites that parts of the campaign assemblage had used. 
Some of these emails were identical; some contradicted each other-a point to which I return below. Informal interviews suggest that my email burden was similar to that of most activists. When I asked people about the amount of email, some were incredulous: "you mean to say you read all that shit? I just ignore it, man". This is just one of several ways of countering overcommunication.

Another was to avoid exposing oneself to communication. One organizer complained that many people would leave meetings without surrendering the email addresses or phone numbers needed to involve them in future activities; perhaps not an unreasonable choice on their behalf, even when they were interested in volunteering. A lot of different information about events could be found online if one looked for it, but if one signed up, it would come looking for one, and try to impose itself on one. People made their own decisions to regulate the push and pull communication to which they submitted themselves, but the group developed few means of doing so. To quote from an email on one of the activist lists: "I'd like to make a suggestion. If you are going to respond to someone, please just direct it to that person only and not the whole listserv. ... [I] don't want to put the energy into clicking on such a response." Despite such pleas, individual, and often private, messages continued to be broadcast to whole lists.

During the final days, volunteers were called up, sometimes early in the morning or late at night, and asked to help with specific events. People would routinely get several emails, or even calls, about the same event. On some occasions, the calls would come as people were finishing or starting other volunteer activities. Nobody seemed to have an overview of who did what at the street level. One counter-strategy is reported by one former volunteer, who confided to me that he had signed off from the various newsletters and sites used by the campaign because he was tired of being "spammed". It is interesting to note that he equivalated communication 
from a campaign with which he actually wanted to be involved with unsolicited and often semifraudulent email. He added, with what seemed to be regret, that this also meant that he did not really get around to doing much anymore. The very means of attachment can lead to detachment.

Those who worked hardest of all were also at the receiving end of the most communication. One organizer pointedly turned off her cell phone at one of the final meetings, as calls kept interrupting her speech. In conversations with activists out on the street, several reported that central organizers no longer answered phone calls or emails regularly, another point that I explore in more detail below. As I left a meeting five days before the election, two young volunteers who had taken on a lot of responsibility in the final month were staring at the fifty or so pages with hand-written personal information and specifications of when and where people would be willing to help with what. One sighed: "I really don't know what to do." These people became human bottlenecks.

Each additional group that joined the campaign would increase the amount of communication, as messages were sent out simultaneously by several organizations using various different forms of communication (Meetup, Facebook, the campaign website, and so on). Around each major event or deadline, new communicators would raise their voice, new forms of communication would be added to the assemblage, and the aggregate amount of communication would increase. It is important to note that it seems to be precisely because of the advantages of Internet communication, its speed, ease, and low cost, that overcommunication became so prevalent. With low front-end costs for the sender, no individual part of the group had an incentive to hold back, cease and desist. Unlike in a formal organization or other kind of hierarchy, no one was in a position to dictate a set of communicative guidelines to direct the flow. And the group did not make any collective attempts to develop and certify a 
communications protocol. So people had to improvize. The more activists the campaign assembled through the Internet, the more pressing the problems became, as more people chipped in on more issues and decisions, and new transaction costs surfaced.

The activists themselves were not the only ones who suffered from problems of overcommunication during the final days. The infrastructure did too. Take the campaign website. The very software that had been designed to make it manageable to navigate the site turned out to be a technological bottleneck when things heated up. For several days, searches for nearby events returned random and incomplete results, as more events were going on than the maximum number of returns one could request from the search database.

The problem of overcommunication was most acute in the final days of the campaign, but every deadline to be met, and every major event, was accompanied by a flurry of cumbersome messages delivered by any means available — email, phone, face-to-face, and via various Internet sites. The activists never found a way to counterbalance the tendency to always communicate more. A few months after the group had mainly been coordinated using Meetup, self-made websites, and email, the official campaign's website was added to the bunch. As things heated up and it became increasingly clear that this site was not suitable for handling large amounts of communication, and that email alone would not do for two-way communication and coordination amongst smaller groups of dedicated activists, a Facebook profile was added. Meanwhile, other people had unilaterally begun to post events on other sites too, like going.com, craigslist, and events.yahoo.com. In the final days, as some key volunteers decided that cloud activism was becoming too cloudy, there was a general retreat from all these platforms, and a move back to a few emails and a lot of phone and face-to-face coordination. Most events were simply no longer posted online. Up to that point, the solution to the problem of overcommunication had always 
been additional communication, leaving it up to activists themselves to devise ways of handling the ever-increasing inflow. And it seems safe to assume that some people were lost each time the groups migrated onwards to new platforms, because this was never announced on the previous platforms (I for one started having a hard time tracking down people to whom I had previously spoken). Old platforms like Meetup and the various self-made websites lingered on—halfintegrated, half-ignored - as new potential volunteers continued to consult them and sign up months after they had ceased to provide an exostructure for the campaign assemblage.

THE PROBLEM OF MISCOMMUNICATION: “OOPS, I MADE A MISTAKE.”

Such would-be new volunteers were among the many at the receiving end of miscommunications. For a long period after it had, for all practical purposes, been abandoned by the activists, the Meetup group that had been set up months before did not point visitors or new members onwards to the new infrastructures, the campaign website and the Facebook profile, let alone to the informal networks of phone and face-to-face communication that coordinated more and more activity. It simply remained there; continuing to give the impression it was a central platform for people interested in joining the campaign.

This example highlights the difficulties people faced as they had to navigate the cloud of several online platforms in their attempt to stay in touch with the group. Apart from a small core group of full-time volunteers, most people were only associated with the campaign through online communication and very occasional offline events for the first several months. When asked how they kept in touch with the group, the standard answer was "the Internet". Until late 
in the game, few events were announced anywhere but online. Yet, for many months, there was no central repository for information, or way of navigating or evaluating the vast expanse of information scattered around the net and various inboxes. When one was provided, its search function did not return all events in the area, because there were too many for its maximum number of hits. People had to seek out different sites, and would then often have to weigh contradictory information and decide how to act on it. Will the event start at $7 \mathrm{pm}$ or $9 \mathrm{pm}$ ? Where will it be? Who should I trust on this? Again, people had to improvise their own responses; no organizational solutions were forthcoming.

These problems may seem trivial, but it is surely off-putting for a potential activist to take time out of a busy schedule to attend a political event, and then find no one there, either because the location reported was wrong or changed at the last minute and nobody had updated the information on a particular platform. Things got even thornier when people were asked to join events where some resource critical to whatever activity was to be carried out was limitedchairs at meetings, tickets for rallies, phones for phone banking, seats in cars driving volunteers. Someone who had taken time off to help with a weekend-long activity outside the area, signed up to do it, and paid for it out of his own pocket, was almost left behind because of a miscalculation as to how many cars would be necessary. A volunteer who came to the phone bank one weeknight, and who had even printed and brought along a sheet that documented that she had signed up online to do so, was turned away and sent home because no phone lines were available. This certainly illustrates Latour's $(1987 ; 2005)$ point that objects are integral to action, and that their absence or scarcity can therefore force inaction. The website through which much of the communication flowed had attracted a potential activist, but miscommunicated when and where help was needed. 
Dissonance between different online sites was not the only source of miscommunication. Discrepancies between these sites and information send out on various email lists further aggravated the problem, and again document the existence of technical bottlenecks. Several of the automated services associated with the sites the activists used seemed to suffer from technical bugs - emails would arrive days after the events they advertised, just as the events listings on the sites themselves would often bring up events that had taken place weeks, even months, earlier. As the problems of miscommunication became clearer to volunteer organizers, they would again typically try to communicate their way out of the problem. The immediate cost was, after all, low. Often, emails would arrive in several incarnations sometimes minutes apart, sometimes days apart, apologizing "oops, I made a mistake, here it is again". Local coordinators tried to solve the problem by establishing their own email lists to communicate with a smaller group, defined perhaps by locality, professional background, or some other affinity. In the end, there were hundreds of these online sub-groups. These lists would rarely be updated in sync with the arrival and departure of activists. As described above, some tried to avoid the deluge by getting off the lists, but, ironically, even getting on the relevant lists could be a problem, since often nobody seemed to know who did what, or even what list to join. Again, a few people, especially towards the end of the campaign, became human bottlenecks, organizing dozens of events, handling several email lists, and trying to update at least a fraction of the online platforms used by the activists.

In the final days, much of the communication moved offline, largely in response to the problems discussed here. Key organizers decided to cut back on what they saw as excessive communication and focus on action instead, coordinated largely by phone and face-to-face meetings. This helped alleviate the problem of overcommunication, but also generated new kinds 
of miscommunication, as an ever-growing number of offline elements were added to the campaign to keep track of and coordinate things. Sign-up sheets on paper supplemented the online sign-up functions, phone trees came to supplement websites and email lists, and it became increasingly clear that no clear correspondence existed between different online and offline clusters of information. At events, regardless of whether it was at meetings or on the street, organizers would joke about the discrepancies between the number of people signed up online, and the actual turnout. For the first several months, the jokes lightened the atmosphere in meetings with many more chairs than people. Yet during the final days, the lack of clarity about the actual number of activists caused severe shortages of cars, signs, leaflets, flyers, or whatever else people needed to accomplish the activity they had signed up for, heard about, been emailed about, or dragged along to.

Despite these problems, many activists continued to praise the potential of the Internet. Stories about the importance of the Internet in the 2004 Dean campaign were aired almost as often among the activists as in academic discussions of Internet politics. One elected official joining the campaign praised the campaign website as a "fabulous tool for organizing" at a public meeting, even as he admitted minutes later that he did not know much about how to use it. His behavior provides a useful illustration: To publicize the event in question, he had set up a separate group on the campaign website, and a separate email list to further spread the word. After all, why not? It is so easy and does not cost anything. Fabulous indeed. Only he had not taken care to check which groups and email lists already existed in the neighborhood, and much to the chagrin of those that did, he had simply added another layer of communication, and further increased the need for coordination that nobody was in a position to provide. The activists would simultaneously praise low-cost communication and narrate the labors that accompanied it. 
THE PROBLEM OF COMMUNICATIVE OVERLOAD: "YOU CAN'T REPEAT THINGS TOO OFTEN."

The last example illustrates that the activist groups had not found an organizational form with the capacity to deal with the labors of Internet-assisted activism. People and groups were overwhelmed. Volunteers ignored emails, postings, and phone calls, and so did organizers and staff members, and when they in turn were frustrated by people's propensity to not show up or to show up in too great a number, they sent more emails, posted more messages, made more phone calls, and made more mistakes along the way.

The various Internet elements that the activists used helped to mobilize people and tie them together in an activist group that was durable and allowed people to join the campaign. But on those occasions where the activists needed to act, these elements served to bind people together in a way that came with a price: communicative overload. You could reach everyone with a click, but so many did this, and with such regularity, and with such different and conflicting messages, that little followed from it. People ignored the contact, because they were at the receiving end of more communications than they, as unpaid volunteers rather than paid employees, could, or wished, to deal with. And in an endless spiral, the solution to the problems of overcommunication and miscommunication was again more communication. As one organizer put it: “you can't repeat things too often". In the days when every repetition came at an up-front costs for the repeater, and 'too often' thus did not mean 'all the time', this may have been a sensible approach. Now, when all it takes is a click, things may be different, and it is 
worthwhile to remember that you can actually repeat things too often. For people started to tune out, or deal only with a sample of the many communications, and the message-to-action ratio seemed to plunge. Several people regretted that they had missed out on an event because they saw the emails too late, or did not see them at all. "I began to just archive stuff", as one activist said after the primary. Others reported that they only read the ones "from the office" (which only coordinated a part of the activity on the ground), or they only read those from activists they knew personally. Others filtered on the basis of principles largely of their own devising. The theoretical idea of information overload, outlined above, illustrates that this problem is hardly unique to activists, and it is part of the reason why, for instance, Facebook imposes limits on how many people one may message, why email accounts come with spam filters, and, why, ironically, according to one press report (Richtel, 2008), some of the biggest technology companies are now banding together to 'fight' the information overload that their very own devices and applications afford.

Leaving aside the problems and defense strategies of individual activists, why did the wider group suffer from communicative overload, and how did it try to deal with it? These problems cannot be attributed to incompetence, since both the activists and the staffers who helped them in the final months had as much technical expertise as one could realistically hope to find in a campaign. Nor do they seem to be due to a lack of resources, as the campaign successfully mobilized large numbers of volunteers and substantial sums of money, and it used many cutting-edge technologies. One cannot even blame the campaign for becoming a victim of its own success. While it certainly did attract a large population of activists, nothing suggests that it was a bigger mobilization success than pre-Internet campaigns waged around grassroots favorites like, say Jesse Jackson, George McGovern or Barry Goldwater. A historical perspective 
reminds us that current mobilization highs are still lows compared to the peaks of the 1960s and 1970s (cf. American National Election Studies surveys, question VCF0719). But, given the number of activists involved, Internet-assisted activism seemed to come with specific problems. The core problems were built in to the very socio-technical form that the group and the wider campaign had assumed.

The heterogeneous campaign assemblage distributed numerous means of communication among many actors with no incentives to refine or withhold information. Despite the low upfront costs of communication, the aggregate costs turned out to be considerable, and, despite the monetary means and the manpower mobilized, occasionally overwhelming. The partly permeable organizational form had drawn people in with promises of openness and encouragements to 'raise your voice'- the campaign site of course provided each registered volunteer with their own blog. But it did not close the loop on all this communication: there was no one to deal with it, no one to sift and sort the vast amounts of material, nor did any emergent lateral order appear in time to sort it all out. As Simon (1971) noted, an abundance of communication leads to a relative scarcity of attention. This phenomenon seems to be a particularly complex challenge for a distributed and non-hierarchical group with no clearly agreed forms of decision-making, and where no one tries to develop a common communication protocol. For instance, how does one deal with the fact that in the metropolitan area of my case study alone, halfway through the period, almost three hundred subgroups had formed online, using the campaign site alone? Dozens were named after the locale, dozens more laid claims to represent various constituencies, and countless were formed by individuals on various idiosyncratic bases. All of these surfaced of one went searching online for information. Inactive groups, events with no one signed up to attend, blogs with no postings, all like unread emails, 
added to the communicative overload. The emergent properties of the assemblage were far removed from frictionless coordination and collective action associated with ideas about 'smartmobs' and the like (Rheingold, 2002).

When it became clear that Internet communication could be paralyzing in terms of actually getting the activists activated, the core of the activist group essentially re-assembled itself through new, and largely offline, forms of associations in the final days. It is hard to tell how many people were left out of the re-assembly as the communicative point of gravity switched from the campaign website, Facebook, Meetup and the rest, and turned to emails and, most importantly, phones and face-to-face coordination. The previously open and collaborative group in a sense lapsed back into non-public and command-based forms of coordination in which a few of the recently arrived campaign staffers and centrally placed veteran activists wielded their symbolic status in attempts to get things done. The last minute re-assembly was partly possible because they had build their repositories of contact information along the way, and they already developed insipient networks of phone and face-to-face association on previous occasions where action had turned out to be easier to pursue offline. Now, these modes of operation defined the activist effort.

I spoke with a volunteer some days after the campaign, and his enthusiasm for Internetassistance had been tempered by the experience. He was glad he could now open his inbox again without dreading an overflow of new messages. In a follow-up conversation a few months later, a key activist coordinator volunteered that the finals days had been "chaotic" and "crazy". I had no chance to quiz the campaign staff, who still ignored my emails and calls—off to be overloaded somewhere else, no doubt. 


\section{CONCLUSION}

The Internet-assisted activism I have analyzed here turned out to be laborious, but it also gave birth to something. A community of interest was maintained for more than a year, and parts of it turned to action too. Tens of thousands of phone calls were made, thousands of leaflets handed out, polls were watched on Election Day, and so on. The labors I have identified here plagued a process, they did not stop it. Nonetheless, thirteen months after I started my field work as a believer in the unproblematic idea of low-cost communication activism, my case had given me a rich data set to problematize it and explore something Garrett (2006, p.218) argues is "largely absent in the literature", namely "empirical analysis of the negative consequences of new ICTs."

To recap, the activists I observed faced three interrelated problems:

(1) Overcommunication: reduced individual up-front costs for communications, more communicators, and an increase in the number of forms of communication generated redundant communication.

(2) Miscommunication: more communications, more communicators, and more forms of communication facilitated more instances of discrepancy between different communications, and/or between what was communicated and what was intended.

(3) Communicative overload: individual activists, their groups, and the wider assemblage they are parts of struggled with more communication than they could or would deal with. 
All three problems are related, and all three increase the transaction costs of activism for reasons that are similar to those that accompany more general problems of information overload. All seem to arise out of precisely what was supposed to be the great advantage of Internet communications - its speed, ease, and low cost. Their empirical reality shows that the proponents of the idea of ICTs in general and various Internet elements in particular as providing low-cost communication for activism have jumped too quickly from lowered up-front and entry costs to the wider question of the total cost of communication, which may have increased more than it has decreased. It would be fascinating to see a comparative and historical study tracking changes in how much time activists spend on communication. The problems identified here are related but also distinct, in that individuals, groups, organizations, and assemblages can suffer from problems of overcommunication and/or miscommunication without facing communicative overload, provided they are willing to dedicate enough social and technical resources to dealing with the incoming flow. And even if one imagines a situation without overcommunication and miscommunication, communicative overload is still a distinct possibility if there is simply too much communication —as the information overload literature points out.

In what sense are these problems the labors of Internet-assisted activism in particular? As historians have pointed out, some people have struggled with information overload since at least the $15^{\text {th }}$ century (cf. Blair, 2003), and organizational sociologists have cautioned against the technologically aggravated problems of organizing in information- and communication-rich environments since at least the 1970s (cf. Simon, 1971). The empirical point that stands out from my case is that it is precisely the Internet elements of the activist group that people complain most vehemently about (not phones or meetings), and that these are the elements that key activists decided to shed in the final days. The single most important problem with the way in 
which Internet elements had become integrated into the activist groups was the proliferation of different forms of online communication, from an initial reliance on Meetup and email to an ever-increasing number of applications ranging from the campaign website to Facebook and more. Earlier exostructures for activism, like the postal system or telephone networks, may also have afforded information overload, but not through equally low-cost communication or the radical decentralization associated with what I have called 'cloud activism'. So something new seems to be afoot. It would have taken very peculiar priorities in activist groups or campaign organizations to generate 45 phone calls or letters in a few days to a single Goldwater supporter in 1964 or a McGovern supporter in 1972. The up-front cost of sending 45 emails in 2008 is trivial, so is the appropriation of numerous forms of communication from the many ICTs make available, and the wider ramifications may not cause the sender, whether an activist organizer or a staffer, a moment's pause. ${ }^{2}$

In the narrative and analysis above, I have highlighted many different individual and group-wide attempts to confront the problems, to alleviate the labors that inhibited both community maintenance and action. People would navigate the flow of information based on trust or reputation (a social logic that many companies today are trying to translate into technical equivalents), by simply ignoring certain streams (improvising their own social spam filters), or by leaving certain platforms altogether. Organizers and groups would not only try to communicate their way out of the problems and thus exacerbate the labors, but also sometimes try to centralize action around one or a few elements, such as the campaign website, or, at the end, face-to-face and phone coordination. Some of these responses were satisfying to some

\footnotetext{
${ }^{2}$ This does not mean that the problems were caused by the Internet (or by specific elements). Though these were integral to the problems, part of the reason they flourished was the mindset behind the idea that you cannot repeat things too often and the organizational forms it lead the activists to adopt. In this case as elsewhere, the social and the technical cannot be neatly separated, but evolve in interdependent ways. Internet-assisted activism, and its labors, is a thoroughly socio-technical phenomenon.
} 
people involved. Those focused mainly on action were quiet pleased with what the group had accomplished by the end of the campaign. Some of the activists had acted collectively. But others, those focused on community, and especially those left out at the end, felt the pangs more keenly, and were left discontent. The character of the campaign assemblage they were part of had changed from an open volunteer-dominated network to a more traditional command-andcontrol operation.

Ways of dealing with these problems had to be found. One irony of the myth of frictionless collaboration peddled by certain professionals is that those professsionals are often the very same people paid to ease the labors and realize the touted potential. My case clearly illustrates how organizing and organizational form, in activism as elsewhere, is communication and is about the organization of communication. The new 'hybrid' (Chadwick, 2007) or 'permanently beta' (Neff \& Stark, 2003) forms of organization that seem to be evolving along with new technologies will have to face problems akin to the ones analyzed here if they are to function effectively in a time of communicative exuberance. Maybe they will. Analysts like Benkler (2006) and Chadwick (2009) remain cautiously optimistic, and it has been noted in economic history that the affordances of new technologies are often only reaped decades after they become widespread, as they are integrated into developing social practices (David, 1990). The same may apply to Internet-assisted activism, a moving target with constantly changing socio-technical forms. That remains to be seen.

Will professional and volunteer organizers face the labors identified here in every kind of setting? I do not think so, and my data and analysis would not allow me to claim this. There are obvious limitations to what kinds of general insights one can firmly establish on the basis of a single case, but I would suggest that activist groups, whether in electoral politics or elsewhere 
are more likely to face these problems if they a) are heterogeneous, including several overlapping communities of both interest and action b) engaged in something that requires sustained action rather than momentary 'flash mobbing' c) do not have a shared set of organizational protocols for communication and d) possess no pre-fashioned infrastructure and exostructure but must fashion their own out of available elements as they go along.

Internet-assisted activism, its labors, and their socio-technical underpinnings and solutions seem likely to stay on the agenda, because Internet elements are becoming increasingly ubiquitous and integral to much social action, and because their affordances are by no means clear. In both politics (Bimber \& David, 2003, p. 166; Foot \& Schneider 2006, p. 155) and civic life more widely (Klein, 1999; Shah et al, 2001), analysts seem to agree that the Internet may be highly effective in facilitating activism. And, as noted above, the political professionals who help define campaign assemblages and their openness to activist participation seem much more open to the idea of citizen involvement today than they did as recently as the 1990s (see Weir \& Ganz, 1997 on the organizational side of this skepticism, and Stromer-Galley, 2000 on the sociotechnical side). But the professionals' interest remains clearly instrumental, and if they come to the conclusion that the socio-technical tools, techniques, and forms of assemblage involving activists are more trouble than they are worth, and the activists themselves are partly paralyzed by problems like the ones analyzed here, the current shift towards collaboration may slide back towards the emphasis on control and management that Howard (2006) highlights in his study of new media campaigns. To avoid this, people who want to pursue Internet-assisted activism have to confront the labors and problems that accompany it, and find ways of dealing with them so they can both assemble and get things done. That, after all, is the goal of activism. 


\section{REFERENCES}

Benkler, Yochai (2006). The Wealth of Networks. New Haven: Yale University Press.

Bennett, W. L. (2003). Communicating Global Activism. Information, Communication \& Society, 6(2), 143. doi: 10.1080/1369118032000093860.

Bimber, B. A., \& Davis, R. (2003). Campaigning Online: The Internet in U.S. Elections. New York: Oxford University Press.

Bimber, B., Flanagin, A. J., \& Stohl, C. (2005). Reconceptualizing Collective Action in the Contemporary Media Environment. Communication Theory, 15(4), 365-388. doi: 10.1111/j.1468-2885.2005.tb00340.x.

Blair, A. (2003). Reading Strategies for Coping With Information Overload ca. 1550-1700. Journal of the History of Ideas, 64(1), 11-28.

Chadwick, A. (2007). Digital Network Repertoires and Organizational Hybridity. Political Communication, 24(3), 283. doi: 10.1080/10584600701471666.

Chadwick, A. (2009). Web 2.0: New Challenges for the Study of E-Democracy in an Era of Informational Exuberance. I/S: A Journal of Law and Policy for the Information Society, 5(1), 132.

David, P. A. (1990). The Dynamo and the Computer: An Historical Perspective on the Modern Productivity Paradox. The American Economic Review, 80(2), 355-361.

De Landa, M. (2006). A New Philosophy of Society: Assemblage Theory and Social Complexity. London: Continuum.

Della Porta, D., Andretta, M., Mosca, L., \& Reiter, H. (2006). Globalization from Below: Transnational Activists and Protest Networks. Minneapolis: University of Minnesota Press. 
Edmunds, A., \& Morris, A. (2000). The problem of information overload in business organisations: a review of the literature. International Journal of Information Management, 20(1), 17-28. doi: 10.1016/S0268-4012(99)00051-1.

Eppler, M. J., \& Mengis, J. (2004). The Concept of Information Overload: A Review of Literature from Organization Science, Accounting, Marketing, MIS, and Related Disciplines. The Information Society, 20(5), 325-344. doi: 10.1080/01972240490507974.

Foot, K. A., \& Schneider, S. M. (2006). Web Campaigning. Cambridge: MIT Press.

Garrett, R. K. (2006). Protest in an Information Society: a review of literature on social movements and new ICTs . Information, Communication \& Society, 9(2), 202-224. doi: 10.1080/13691180600630773.

Gould, R. V. (1995). Insurgent Identities: Class, Community, and Protest in Paris from 1848 to the Commune. Chicago: University of Chicago Press.

Himma, K. (2007). The concept of information overload: A preliminary step in understanding the nature of a harmful information-related condition. Ethics and Information Technology, 9(4), 259-272. doi: 10.1007/s10676-007-9140-8.

Hindman, M. S. (2008). The Myth of Digital Democracy. Princeton: Princeton University Press.

Howard, P. N. (2006). New Media Campaigns and the Managed Citizen. Cambridge and New York: Cambridge University Press.

Johnson, D. B., \& Gibson, J. R. (1974). The Divisive Primary Revisited: Party Activists in Iowa. The American Political Science Review, 68(1), 67-77.

Klein, H. K. (1999). Tocqueville in Cyberspace: Using the Internet for Citizen Associations. The Information Society, 15(4), 213-220. doi: 10.1080/019722499128376. 
Latour, B. (1986). The Powers of Association. In J. Law (Ed.) Power, Action and Belief. A new sociology of knowledge? (pp. 261-277). London: Routledge \& Kegan Paul.

Latour, B. (1987). Science in Action: How to Follow Scientists and Engineers Through Society. Cambridge: Harvard University Press.

Latour, B. (2005). Reassembling the Social: An Introduction to Actor-Network-Theory. Oxford: Oxford University Press.

Neff, G., \& Stark, D. (2003). Permanently Beta: Responsive Organization in the Internet Era. In P. N. Howard \& S. Jones (Eds.), Society Online: The Internet In Context (pp. 173-188). Thousand Oaks: Sage.

Rheingold, H. (2002). Smart Mobs: The Next Social Revolution. Cambridge, MA: Perseus Publishing. Roscigno, V. J., \& Danaher, W. F. (2001). Media and Mobilization: The Case of Radio and Southern Textile Worker Insurgency, 1929 to 1934. American Sociological Review, 66(1), 21-48.

Shah, D. V., Kwak, N., \& Holbert, R. L. (2001). "Connecting" and "Disconnecting" With Civic Life: Patterns of Internet Use and the Production of Social Capital. Political Communication, 18(2), 141. doi: $10.1080 / 105846001750322952$.

Shenk, D. (1997). Data Smog: Surviving the Information Glut. San Francisco, Calif.: HarperEdge. Shumate, M., \& Pike, J. (2006). Trouble in a Geographically Distributed Virtual Network Organization: Organizing Tensions in Continental Direct Action Network. Journal of Computer-Mediated Communication, 11(3), article 8.

Simon, H. A. (1971). Designing Organizations for an Information-Rich World. In M. Greenberger (Ed.), Computers, Communication, and the Public Interest (pp. 37-72). Baltimore: The Johns Hopkins Press. 
Snow, D. A., Zurcher, L. A., \& Sheldon Ekland-Olson. (1980). Social Networks and Social Movements: A Microstructural Approach to Differential Recruitment. American Sociological Review, 45(5), $787-801$.

Sreberny-Mohammadi, A., \& Mohammadi, A. (1994). Small Media, Big Revolution: Communication, Culture, and the Iranian Revolution. Minneapolis: University of Minnesota Press.

Stromer-Galley, J. (2000). On-Line Interaction and Why Candidates Avoid It. Journal of Communication, 50(4), 111-132. doi: 10.1111/j.1460-2466.2000.tb02865.x.

Tilly, C. (2004). Social Movements, 1768-2004. Boulder: Paradigm Publishers.

Trippi, J. (2004). The Revolution Will Not Be Televised: Democracy, the Internet, and the Overthrow of Everything. New York: Regan Books.

Vaccari, C. (2008). From the air to the ground: the internet in the 2004 US presidential campaign. New Media \& Society, 10(4), 647-665. doi: 10.1177/1461444808093735.

Verba, S., Schlozman, K. L., \& Brady, H. E. (1995). Voice and Equality: Civic Voluntarism in American Politics. Cambridge: Harvard University Press.

Weir, M. \& Ganz, M. (1997). Reconnecting People and Politics. In T. Skocpol \& S. Greenberg (Eds.), The New Majority (pp. 149-171). New Haven, Yale University Press.

Zeldes, N., Sward, D., \& Louchheim, S. (2007). Infomania: Why we can't afford to ignore it any longer. First Monday, 12(8). Retrieved from http://firstmonday.org/htbin/cgiwrap/bin/ojs/index.php/fm/article/view/1973/1848. 